\title{
The Use of Facility Dogs to Bridge the Justice Gap for Survivors of Sexual Offending
}

\author{
Elizabeth Spruin ${ }^{1, *}$, Katarina Mozova ${ }^{2}$, Tammy Dempster ${ }^{1}$ and Rachel Freeman ${ }^{3}$ \\ 1 Department of Psychology, Canterbury Christ Church University, Canterbury CT1 1QU, UK; \\ Tammy.dempster@canterbury.ac.uk \\ 2 Department of Policing, Canterbury Christ Church University, Canterbury CT1 1QU, UK; \\ katarina.mozova@canterbury.ac.uk \\ 3 Kent Police, Maidstone ME15 9BZ, UK; Rachel.Freeman@kent.police.uk \\ * Correspondence: liz.spruin@canterbury.ac.uk
}

Received: 20 May 2020; Accepted: 4 June 2020; Published: 8 June 2020

\begin{abstract}
The current study investigated the support that a facility dog can provide to survivors of sexual crimes when undergoing video-recorded police interviews. In total, 13 survivors of sexual offences, who were undergoing a video-recorded interview, were provided with a facility dog for the interview process. For each case, data were collected via interviews, observations and surveys. Using a multiple case study approach, qualitative data were analysed to identify patterns, with observational and survey data used to provide further support to these outcomes. A total of four main themes emerged from the data: (1) a change in focus for the survivor, (2) a difference in the survivors' engagement, (3) the dog as a comforter to keep the survivor calm and (4) a positive environment. Overall, the findings suggest that the facility dog provided a much needed and beneficial service to survivors, helping them feel calmer and more comfortable. The dog also provided survivors with a more positive environment, allowing them to focus on the interview and communicate more openly about their experiences. The current study, therefore, presents very positive findings relating to improving survivors' perspectives of justice within the framework of kaleidoscopic justice, bridging their perceived justice gap.
\end{abstract}

Keywords: facility dogs; video-recorded interview; survivors of sexual offences; kaleidoscopic justice

\section{Introduction}

According to the latest data presented by the Office for National Statistics (Office for National Statistics 2019), in the UK, there were 163,076 sexual offences recorded by the police in 2019 for survivors over the age of 16; and 73,818 incidents of sexual abuse and exploitation reported for children. Whilst the prevalence of serious sexual offending seems to have been somewhat stable over the last few years, continuous calls for improving the journey of survivors have not yet been effectively answered, with less than one in five survivors over the age of $16(17 \%)$ ever reporting an offence to the police, a rate which is only a small improvement (from 15\%) from almost a decade ago (Office for National Statistics 2013). The rate of reporting of child sexual offences is estimated even lower, at one in eight (Children's Commissioner 2015). The reporting of sexual offences, therefore, remains to be among the lowest nationally.

Of those who do report to the police, approximately half do not proceed past the investigation stage due to insufficient evidence. Whilst the reasons for attrition rates vary and it is not clear how many cases fail due to the survivor not wanting to give evidence, statistics suggest that in $28 \%$ of cases, where the suspect is identified, the survivor does not support taking action (Office for National Statistics 2018). Through rape attrition studies specifically, we also know that survivor withdrawal accounts for a large 
proportion of the attrition problem (e.g., Hester 2013). The police-survivor relationship also plays a key part, and positive experiences, through providing comfort and support to the survivor, were even shown to increase the likelihood of a survivor providing a video-recorded statement by four and a half times (Hohl and Stanko 2015). Among others, the importance of addressing survivor well-being is vital, as the trauma they experience through the offence can be further exacerbated as a result of the investigation process (Brooks and Burman 2017; Burman 2009; Maier 2008), resulting in survivors becoming too distressed to engage with the investigation (Office for National Statistics 2019). Recently, McGlynn and Westmarland (2018) coined the term 'kaleidoscopic justice' to explain the justice gap for survivors of sexual offending. In their research, it became clear that survivor perceptions of justice relate not only to conviction, but also wider processes which are shifting in importance and need to be better understood. Survivor well-being was highlighted as one such key process. The aim of the current study is, therefore, to provide the first in-depth evaluation of a facility dog service, in which the principle scope is to provide the much-needed emotional support to survivors of sexual offences. To do so, a qualitative research approach is utilized in order to holistically explore this nuanced form of support, specifically provided during the stage of having to provide evidence relating to the offence, in line with the Policing Vision 2025 (National Police Chiefs' Council 2016) relating to improving policies for victims.

\subsection{The Survivor Journey}

A more realistic figure of sexual offending emerges through the Crime Survey for England and Wales (CSEW) which points to around 3.4 million female, 631,000 male and 669,000 child survivors (Office for National Statistics 2019). These estimates highlight the significance of improving the criminal justice journey for survivors, where evidence provided by survivors is crucial, yet their perceptions of the system tend to be worrying (Svedin and Back 2003). This is likely, in part, due to the barriers that survivors face in not only bringing their case forward to authorities, but also seeing a successful outcome (Antaki et al. 2015). For over 40 years, research has consistently found that compared to other offences, sexual offence cases are less likely to be reported, to progress to prosecution, and to lead to a conviction (e.g., Grace et al. 1992; Gregory and Lees 1999; Hohl and Stanko 2015; Kelly et al. 2005; Wright 1984). While attempts have been made over the years to shift police practices in regards to the treatment and recording of sexual offending, these changes have done very little to reduce attrition rates (Hohl and Stanko 2015; Lea et al. 2003). In more recent years, however, the government has concerted their efforts on the criminal justice approach to dealing with sexual offences, noting the need for a more 'victim-focused' strategy to ensure that their needs are put first and their well-being is protected (HMIC/HMCPSI 2012).

Subsequently, key provisions have been introduced across the Criminal Justice System (CJS) to help improve the treatment and outcomes of sexual assault and rape survivors. This included introducing new policing roles and teams, such as the Sexual Offences Investigative Trained Officers (SOITOs) (McMillan 2014; Westmarland and Ganjoli 2012) or dedicated support services, including Rape Crisis Centres (RCCs) and Sexual Assault Referral Centres (SARCs), where medical and psychological care is the primary focus. Specialised advocacy services were also created; for example, Independent Sexual Violence Advisers (ISVAs) assist victims in their interactions with the criminal justice system, health and other agencies (Brooks and Burman 2017). Further, Special Measures were introduced under the Youth Justice and Criminal Evidence Act (1999) which provide survivors of sexual offences the opportunity to have an enhanced level of support when providing evidence, thus aiming to make the process less daunting for them, while also improving the quality of evidence (Hamlyn et al. 2004a, 2004b). Of particular note to this study is the provision of a 'video-recorded interview' under Section 27 of the Act, enabling survivors to give evidence out of court, sparing them the stress of testifying in person (Baverstock 2017). 


\subsection{The Video-Recorded Interview}

The provision of giving evidence via a pre-recorded video interview was aimed at decreasing the possibility of secondary victimisation, as giving evidence in court was seen among the most daunting elements of the whole process (McEwan 2005), not benefitting victims or the interest of justice (Rape Crisis Network 2018). The reasoning behind utilising video-recorded interviews and the Achieving Best Evidence (ABE) approach to interviews (Hill and Davies 2012) relates to stress having a negative impact on a victim's ability to accurately recall evidence (Deffenbacher et al. 2004). The video-recorded interview is at times informally referred to as an ABE interview due to the interviewing technique utilised. It has been shown that these procedures not only reduce stress and the risk of re-traumatisation, but also help in the recall of evidence (Baverstock 2017). Konradi (1999) further added that video-recorded evidence may enhance the quality of information because many victims report that in the courtroom, they often concentrate on controlling their emotions, rather than focusing on their testimony. Research supports these notions in that the vast majority (91\%) of victims who have given video-recorded evidence in chief have found it helpful. Survivors of sexual offences noted particularly positive reactions, with $44 \%$ of them stating that without it, they would not have been willing or able to give evidence (Hamlyn et al. 2004a). Legal experts further argue that courtrooms are often too intimidating for many victims (Mulcahy 2010) and the notion that vulnerable victims should publicly provide oral evidence is inhumane and unjustified, as it can be particularly distressing for them (McEwan 1990). Many advocates, therefore, contend that video-recorded evidence should be standard practice for vulnerable victims (including victims of sexual crimes) (Maguire et al. 2007).

\subsection{What about the Perceived Justice?}

While Special Measures have shown to improve the overall experiences and satisfaction of vulnerable victims, with video-recorded evidence considered one of the most highly regarded and necessary measures (Home Office 2006), vulnerable victims still seem to be significantly less satisfied compared to other victims (Home Office 2004). Despite the available guidelines, police officers themselves question their real-life applicability as relating to evidence obtained, but also the relationship between survivors and officers (Hanway and Akehurst 2018). As such, despite the significant progress that has been made to improve the support provided to survivors of sexual crimes, research continues to highlight that their needs are still not being fully met (McGlynn et al. 2016), are ineffective in reducing attrition (Brown 2011; Jordan 2011), and survivors' procedural justice needs are not understood (Wemmers et al. 1995). Recent government reports further echo these claims; for instance, the Victims' Commissioner (2016) and the Victims Strategy (HM Government 2018) highlighted the lack of support for survivors during the investigation stages and contended that more research needs to be carried out on support services for survivors of sexual crimes, taking into consideration the voice of those involved. The report further identified positive links between victim satisfaction and providing forms of emotional support that positively alter cognitive states. These concerns have been echoed internationally for years, with the 2012/29/EU Directive (European Parliament and Council 2012) noting the importance of support and protection for victims of crime, placing specific focus on especially distressing crimes, such as those sexual in nature, for children and adults. The need for better services for victims is also highlighted in the Policing Vision 2025 (National Police Chiefs' Council 2016) which all police services across the country should work on achieving.

Based on the provisions briefly outlined above, it is clear that survivors of sexual offences need to be better prepared and supported in order to give their best evidence, as this would help increase the credibility (i.e., believability) of their case and the likelihood of it progressing forward within the CJS. Providing such support could thus lead to more cases being prosecuted and more survivors potentially being spared from testifying in court, thereby reducing the trauma of secondary victimisation. Research on conveying witness credibility has suggested that clear and fluent communication, along with maintaining a relaxed and confident state, are key factors (Boccaccini and Brodsky 2002). For many survivors of sexual crimes, however, these characteristics are often hard to convey due to the heightened 
level of fear and anxiety that is exacerbated by their traumatic experiences (Campbell and Wasco 2005). This can subsequently impede a survivor's concentration and memory, along with their physiological responses, all of which can impact their ability to appear credible (Halligan et al. 2003). Whilst it has been shown earlier that the existing provisions are somewhat effective, though in only a limited manner, finding new ways in improving survivor comfort and emotional support to mitigate the negative responses is much needed and currently lacking (e.g., Victims' Commissioner 2016). Overall, we are currently not yet allowing survivors of sexual crimes to be appropriately equipped to provide the police with a credible account and experience the justice they should receive; this is likely why we are not seeing much change on issues like attrition (McGlynn and Westmarland 2018; Wemmers et al. 1995).

The problem with appropriately addressing this justice gap that survivors of sexual crimes are experiencing lies in the often narrow perception of what it means for a survivor to be satisfied with a case. Research has been consistently finding that survivors do not only have the final outcome of a case in mind (e.g., conviction; Brooks and Burman 2017), but they also want their voice heard, they want dignity, validation and offender accountability. This is encompassed in a theoretical framework portrayed by McGlynn and Westmarland (2018) who, through talking to survivors, present the idea of 'kaleidoscopic justice', imitating the functions of a toy which works in a way that it always shows an unpredictable and ever-changing pattern. Whilst this framework rightly suggests that the experience of every survivor is different, what has been consistently shown, as seen earlier, is that survivor well-being and their treatment through the criminal justice process needs to be addressed. McGlynn and Westmarland (2018) found that issues like dignity, giving survivors their voice, and caring for survivor well-being are perceived as some of the core patterns within the metaphorical kaleidoscope. As such, if we want to improve the criminal justice journey for these individuals, it is vital that these factors are considered, which is a core aim of the current study. Improving the journey of survivors of sexual offending can only be achieved if a balance is found between the seemingly competing agendas of the police (e.g., obtain evidence) and survivors (e.g., in light of kaleidoscopic justice). Whilst official guidance does not count survivor well-being as a top priority for the police (e.g., above discussed ABE guidelines), it is still their core role to see a criminal investigation through to prosecution. Hence, capturing views of processes by both survivors and police officers is crucial in creating strategies which can be utilised in real life.

\subsection{Facility Dogs as a Form of Quiet Companionship and Support}

One promising approach which can help to not only meet the emotional needs of survivors during the investigation process, but also assist them in remaining calm and comfortable during their video-recorded interview, is the use of facility dogs (also known as Justice Facility Dogs). These dogs are specially trained to provide non-judgmental companionship to victims and witnesses, assisting them to remain calm so that they can cognitively process and coherently communicate their evidence (Spruin et al. 2016). Facility dogs are graduates of training schools accredited by Assistance Dogs International (ADI), and while they have the same degree of training as service dogs (e.g., guide dogs, hearing dogs), unlike service dogs, who are trained to help one person with a disability, Justice Facility Dogs work alongside legal professionals assisting many people. The dogs typically receive approximately two years of training, which involves learning how to quietly support those experiencing stress, and working with a number of people in high-stress environments, including court, police interviews, and medical examinations (Spruin and Mozova 2018). While the practice of using facility dogs is a novel and innovative idea in the UK, with currently only one ADI-accredited dog working in the legal system with Kent Police, the practice has been widely successful across the United States (229 dogs in 40 states) and Canada (45 dogs in 8 provinces) for over 15 years (Courthouse Dogs Foundation 2019).

The general therapeutic benefits that dogs provide humans have been well-researched over the years (e.g., Barker et al. 2016; Damon and May 1986; Majić et al. 2013; Zimmer 2014), particularly for vulnerable people, including children (Daly and Morton 2006) and adults with cognitive impairments 
(Walsh et al. 1995), attention deficit hyperactivity disorder (Schuck et al. 2013), autism (O'Haire 2013), and depression and brain injuries (Stapleton 2016). For instance, research has consistently shown that dogs can help decrease anxiety and stress, increase confidence and self-esteem under various types of duress (Crenshaw 2011; Dellinger 2009), and integrate information in a more efficient and profound manner, allowing more effective communication (Chandler 2012). Dogs have also been shown to increase feelings of security and warmth, reduce feelings of isolation, and regain control in stressful situations (Wells 2009), thereby making people feel more comfortable and calm (McNicholas and Collis 2006). In fact, dogs have been shown to surpass any other type of animal (including human) in their ability to provide unconditional support (Sanders 2003).

Despite the abundance of research highlighting the benefits of the human-canine relationship, there is limited research into the potential benefits that dogs can provide victims within the CJS. Specifically, there have only been two studies, carried out in the UK, which have examined the utility of therapy dogs in court waiting rooms (Spruin et al. 2019b) and on the court experiences of survivors of sexual crimes (Spruin et al. 2019a). While both studies highlighted the positive impact that therapy dogs can have on the emotional well-being of victims and witnesses, along with the influence they have on reducing anxiety, stress and the fears associated with going to court, the focus of these studies was on the presence of pet therapy dogs, who are not purposely bred or professionally trained to work with vulnerable people or within high-stress environments, unlike ADI-trained facility dogs (Spruin and Mozova 2018). One of the challenges highlighted in the two studies was the length of support therapy dogs can provide, highlighting the need for the use of facility dogs. With that, both studies also had a number of methodological limitations which need to be considered. For instance, the findings from Spruin et al. (2019b) were based on very short, semi-structured interviews with 117 court users; these data also relied entirely on the participants' own views and so there is a need for a more objective evaluation of such impact. Likewise, the study carried out by Spruin et al. (2019b), relied on data from five case studies from one local court, the sources of evidence for these case studies primarily came from observational data, and short, semi-structured interviews with participants. In the context of police interviews (i.e., video-recorded interviews), there has been one study, carried out in the USA, which utilised a trained facility dog. The study found that the dog had a stress-reducing effect for children undergoing police interviews for allegations of child sexual abuse (Krause-Parello et al. 2018). Whilst this study presented support for the use of facility dogs, the methodology did not allow for an understanding of the processes behind the positive impact. Some anecdotal evidence also exists, showcasing the benefits that facility dogs have in supporting victims of crime (e.g., Dellinger 2009; Sandoval 2010; Weems 2013).

\subsection{The Present Study}

To date, there has only been one study, globally, which has investigated the effects of facility dogs within police interviews (Krause-Parello et al. 2018) and no studies in the UK utilising a facility dog within a court or police interview setting. As such, based on recent government reports and academic literature emphasising the need for more emotional support during the investigation stages for survivors, coupled with the literature contending that video-recorded evidence in chief is helpful and should be standard practice for vulnerable victims (Maguire et al. 2007), the current study explores the use of a facility dog for survivors of sexual crimes when undergoing a video-recorded interview.

As research involving personal and sensitive topics, particularly in the CJS, often relies on low participant numbers (e.g., Quas and Goodman 2012; Wheatcroft et al. 2009) and also, due to the limited number of facility dogs working in the UK (i.e., one dog working with Kent Police), a multiple case study approach was implemented (Yin 1994). This approach allows for exploration of a phenomenon within its natural context and is the ideal methodology when holistic, in-depth understanding is needed (Tellis 1997). It further allows for a variety of data sources to be utilised, enabling multiple facets of the phenomenon to be revealed and understood (Yin 2003). This is particularly important for the current study, as it allowed for the voices of those involved within a case (e.g., victims, 
police, family) to be considered. This is something that is not only lacking within current literature but is also an important factor that has been raised by the Victims' Commissioner (2016) review on What Works in Supporting Victims of Crime; the Getting it Right for Victims and Witnesses report (Ministry of Justice 2012); and wider literature, all of which note the neglect of survivor voices in research (e.g., McGlynn and Westmarland 2018).

The current research, therefore, intends to fill in the gaps presented in the literature above, providing the first in-depth exploration into the use of facility dogs within a criminal justice setting. The overall aim of the study was to investigate the support that a facility dog can provide to survivors of sexual crimes when undergoing video-recorded interviews utilising the ABE interview method. This multiple case study design is guided by two core research questions: (1) What is the perceived impact of a facility dog by those directly involved with a specific case, including survivors, supporting individuals, and professionals? and (2) What changes can be observed in survivors' behaviour and state management through the introduction of this service?

\section{Materials and Methods}

\subsection{Design}

As the research focused on exploring the support facility dogs can provide survivors of sexual crimes when undergoing video-recorded interviews, a multiple case study design was implemented (Stake 1978), as this is considered one of the most robust methods for in-depth investigations into complex issues. The method also allows for the integration of various sources of information, capturing meaningful and elaborate data in a holistic and applied context (Yin 1984; Yin 1994), while also permitting one data type to validate the findings of another, providing greater confidence and validity within the results (Tashakkori and Teddlie 2003).

\subsection{Participants}

\subsubsection{Survivors}

As the focus of this research was on survivors of sexual offences, purposive sampling was employed to recruit participants. In this case, participants were chosen for a special situation based on judgement by an expert (Ishak and Bakar 2013). More specifically, the police officer who was interviewing the survivor suggested participants who they believed were particularly vulnerable and had been a survivor of a sexually-orientated crime. This method of sampling is one of the most commonly used sampling strategies for qualitative data, and sample sizes are determined based on saturation achieved from the data themselves (Patton 1990). Yin (2003) suggests that within a multiple-case study design, six to ten cases are a sufficient sample size if the results turn out as predicted. As such, once saturation was achieved across the selected cases, no further data were collected.

In total, 13 survivors of sexual offences, who were undergoing a video-recorded interview by an ABE-trained police officer, were provided with a facility dog for the interview process. There were 13 survivors (11 female, 2 male), and therefore, 13 cases in total, all of whom identified as white British. Their ages ranged from 7 to $27(\mathrm{M}=14.2, \mathrm{SD}=5.70)$. As previously mentioned, all participants were survivors of a sexual crime, which included: sexual offences $(n=8)$, rape $(n=3)$, and sexual assault $(n=2)$. In terms of further vulnerability, the majority of survivors $(n=9)$ also had a diagnosed disability or disorder, which included: autism $(n=4)$, learning difficulties $(n=2)$, attention deficient hyperactivity disorder $(n=2)$, and anxiety disorder $(n=1)$. The researchers are mindful that the demographic composition of the sample is homogenous in some respects (e.g., race), though this was reflective of the cases represented within the Kent Police during the data collection period. 


\subsubsection{Interviewing Officers}

There were a total of 10 interviewing officers from Kent Police, working across the 13 cases (P2 and P12 were interviewed by the same officer; and P6, P7, and P8 were all interviewed by the same officer). In order to make it clear which survivor/case the officers are referring to in the qualitative analysis section, these officers have been given a different ID for each case they worked on rather than using one ID per officer (e.g., P2a is referred to as 'P2a' when she is talking about witness P2's case and as 'P12a' when she is referred to in relation to witness P12's case). Most of the interviewing officers were female $(n=8)$, identified as white British $(n=9$ with $n=1$ identifying as white non-British), and ranged from $35-56$ years old $(\mathrm{M}=40.7 ; \mathrm{SD}=6.0)$. The number of years' experience the officers had on the job ranged from $1-19$, although the average was 6.4 years (SD $=5.8)$.

\subsection{Data Collection}

In order to obtain a rich and comprehensive source of data, a triangulation approach to data collection was chosen (Oliver-Hoyo and Allen 2006). This included collecting data via interviews, observations, and surveys.

Semi-structured interviews were carried out with the parent or guardian who was supporting the survivor throughout the police interview process. The interviews focused on topics relating to each respondent's perceptions of the survivor in relation to their current experiences, the impact they felt the dog may have on the police interview process, and also their feedback on the service that the facility dog provides. These interviews were necessary to create a greater understanding and context (Greene and Hogan 2005) to the survivors' experiences, while also providing some insight into perceived causal inferences (Yin 1994).

Observational data were collected from the survivor's initial contact with the facility dog until they proceeded to their police interview. This included interactions that the survivor had with the dog and also the dog's behaviour throughout the process. To ensure reliability of the observations, two researchers gathered this data independently (Yin 1994). A structured observation schedule was created for the observations and notes were also taken to further emphasise these observations. Only those observations that were recorded by both researchers were used in view of utilising investigator triangulation to improve validity (Stake 1995). These observations provided a greater richness and understanding to the interviews (Creswell 2007), as it enabled an alternative perspective that could not be obtained by relying exclusively on interview data (Maxwell 2012).

Survey data were collected from survivors to further delineate associations between the facility dog and the victims' experience, while also corroborating evidence to enhance data credibility of the other data sources (Patton 1990). Survivors completed a brief survey both before meeting and interacting with the facility dog and then after interacting with him. The survey consisted of 10 questions relating to the victim's current emotional state, which were measured on a 4-point scale ('not at all' to 'very much'). Six questions ('I feel ... calm/tense/upset/relaxed/content/worried') were derived from Marteau and Bekker (1992) 6-item State Trait Anxiety Inventory (STAI-Y6). Four additional questions ('I feel ... frightened/traumatised/safe/supported) were created for use in this study based on guidance provide by the Ministry of Justice (Ministry of Justice et al. 2013), which highlighted the importance of making victims feel safe and supported, as they may be frightened of authority figures and traumatised by their crime. In addition to these 10-items, before meeting the dog, victims were asked an additional open-ended question about their feelings towards their police interview and the presence of the dog.

Further qualitative data were collected from both survivors and interviewing officers. For survivors, upon completion of the police interview, they were asked to provide qualitative feedback in regards to their overall thoughts on the presence of the dog, further reflecting on the items on the survey. For officers, prior to the interview, interviewing officers were asked why they requested the facility dog and in what way they believe the dog may impact on the survivor and interview process. After the interview, they were asked to provide qualitative feedback in regards to their overall thoughts on the presence of the dog, the impact they perceived the dog to have and any further recommendations or 
issues. In cases where an intermediary supported a survivor (more in the procedures section), they were also asked for feedback following the interview.

\subsection{Ethics}

The study was conducted in accordance with the Declaration of Helsinki and was approved by the Ethics Chair of the Faculty of Social and Applied Sciences at Canterbury Christ Church University, who confirmed that the study complied with the University's Research Ethics and Governance Procedures (ethical approval code-16/SAS/356F).

\subsection{Procedures}

Following ethical approval, a small number of ABE-trained police officers $(n=10)$ who conduct video-recorded interviews for Kent Police were informed about the facility dog. They were asked to contact the researchers prior to conducting a video-recorded interview in cases where the presence of the dog was deemed suitable (e.g., no genuine fears or allergies). Once officers identified and approached potential participants, they were asked to complete a brief survey detailing the reasons behind the request for the facility dog (e.g., could help with the victim's anxieties). If survivors verbally agreed, the officer provided them with information about the research, detailing the purpose and aim of the study, as well as a picture of the dog and the research team prior to engaging with the team.

On the day of each police interview, survivors arrived at the police station and were escorted to a private waiting area. Informed consent was gained from survivors prior to data collection. They were also informed about the voluntary nature of their involvement, as well as anonymity and confidentiality of responses and their right to withdraw at any point. Survivors were further told that observational data would be collected by researchers. Survivors were then asked to complete a brief 10-item survey about their current emotional state. After, they were introduced to the facility dog. The dog used for this specific study was a 3-year-old Labrador-Retriever (Oliver). He is an ADI- accredited facility dog who had been professionally trained to provide quiet, non-judgmental companionship to vulnerable people in the criminal justice system. He was presented to survivors as a quiet companion, ensuring he is not presented as an incentive and is not provided with human characteristics, so that his presence cannot impact on further legal proceedings. After engaging with the dog for approximately 15-20 min, survivors were again asked to complete the brief 10-item survey, before going into their official video-recorded interview with the facility dog.

While survivors were in their police interview, semi-structured interviews were carried out with the parent or guardian that was supporting the victim (mother $(n=10)$, father $(n=1))$. The interviews ranged in length from 24 minutes to 3 hours $(M=61.9, S D=39.1)$, this was dependent on the length of the survivor's police interview, as once survivors were done with their interviews, they were escorted back to their family, at which point the interview ended. Upon completion of the police interview, both the survivor and interviewing officer were asked to provide qualitative feedback on the presence of the dog and any impact they believed the dog had. As all survivors were considered to be vulnerable victims, a number of them had an intermediary $(n=4)$ to help facilitate communication between the interviewing officer and the survivor. Intermediaries that were involved were also asked at the end of the interview to provide any verbal feedback they had. Once all the feedback was collected, survivors were then provided with the opportunity to say goodbye to the facility dog, after which they were debriefed and thanked for their time.

\section{Results}

\subsection{Data Analysis}

The main source of data came from the semi-structured interviews with family members and the qualitative feedback provided by survivors and the interviewing officers. The observational and survey data were thus used as corroborating evidence to enhance data credibility of the qualitative 
data (Patton 1990). In order to conduct a rigorous case study, it is key that a suitable analytic strategy is chosen and followed (Yin 1994). The steps suggested by Leedy and Ormrod (2001) were therefore used to analyse all data collected. These steps were broken down into three distinct phases. Firstly, facts pertaining to each case were organised to provide a descriptive overview (see Table 1). A "case" refers to a single case study and comprises of data collected from: the survivor for whom the facility dog was requested, their interviewing officer, and any additional support who accompanied them (i.e., intermediary, parent). Secondly, the qualitative data, which included the semi-structured interviews and qualitative feedback, were analysed to identify patterns that occurred across all cases. Once patterns were established, the observational data were incorporated to provide a greater understanding of each theme. Thirdly, the survey data were analysed using IBM SPPS Statistics for Windows, version 24 (IBM Corp, Armonk, NY, USA) to provide further support to the outcomes.

\subsection{Qualitative Data}

The qualitative data collected were analysed using thematic analysis (Braun and Clarke 2006). To ensure the analysis was inductive, driven by the data, and not inadvertently biased by the preconceptions of the researchers who had designed the study, the data were analysed by an independent researcher who had not been involved in the study design or data collection stages (Braun and Clarke 2006). The coding of themes was therefore carried out without knowledge of the researchers' expectations of the project (Silverman 2013), ensuring a strong process of analytical credibility, and reliability was sustained across the interpretation of the data (Gibbs 2002). Following Braun and Clarke (2006) guidelines, the analysing researchers first read and then re-read the data in order to familiarise themselves with the content, noting down initial thoughts. On the next set of re-reads, codes were created based on the topic of each line of data and then the codes were grouped together in order to identify potential themes and sub-themes. Only those themes which appeared in more than half of the cases are discussed within the results.

A total of four main themes emerged from the data: (1) a change in focus for the survivor, (2) a difference in the survivors' engagement, (3) the dog as a comforter to keep the survivor calm, and (4) a positive environment. Once themes were highlighted, they were refined with sub-themes where applicable. Each theme and corresponding sub-themes are presented below with example quotes from the interviews and qualitative responses (see Table 2 for an overview). It is important to note that the aim of the study was to capture shared experiences among all those involved in the cases. However, as noted in the literature review, it is important to recognise that different actors may have a different understanding of what constitutes success as relating to the use of the facility dog. The focus on shared experiences is an important one, as it is key that strategies are developed which enable success for all involved. However, in light of the possibly different objectives of the involved parties, the description of the themes is enhanced with this in mind. 
Table 1. Overview of each case including type of crime, survivor demographics, and who was present on the day of the police interview.

\begin{tabular}{|c|c|c|c|c|c|c|c|c|}
\hline \multicolumn{5}{|c|}{ Survivor Details } & \multirow[b]{2}{*}{ Additional Support Present } & \multirow[b]{2}{*}{ Officer Title } & \multirow[b]{2}{*}{ Officer Gender } & \multirow[b]{2}{*}{ Police Interview Length } \\
\hline ID & Type of Crime & Age & Gender & Additional Info & & & & \\
\hline P1 & Sexual assault & 16 & $\mathrm{~F}$ & & Father (P1b) & Police Constable (P1a) & $\mathrm{M}$ & $45 \mathrm{~min}$ \\
\hline P2 & Sexual offences & 12 & $\mathrm{~F}$ & ADHD & Mother (P2b) & $\begin{array}{l}\text { Detective Constable-Child } \\
\text { Protection (P2a) }\end{array}$ & $\mathrm{F}$ & $60 \mathrm{~min}$ \\
\hline P3 & Sexual offences & 16 & $\mathrm{~F}$ & & Mother (P3b) & Police Constable (P3a) & $\mathrm{F}$ & $45 \mathrm{~min}$ \\
\hline $\mathrm{P} 4$ & Sexual offences & 21 & $\mathrm{~F}$ & $\begin{array}{l}\text { Learning } \\
\text { difficulties }\end{array}$ & No one & Detective Constable (P4a) & M & $70 \mathrm{~min}$ \\
\hline P5 & Sexual offences & 7 & $\mathrm{~F}$ & & Mother (P5c); Intermediary (P5b) & $\begin{array}{l}\text { Detective Constable-Vulnerable } \\
\text { Investigation Team (P5a) }\end{array}$ & $\mathrm{F}$ & $65 \mathrm{~min}$ \\
\hline P6 & Sexual offences & 8 & $\mathrm{M}$ & ADHD & Mother (P6c); Intermediary (P6b) & Detective Constable (P6a) & $\mathrm{F}$ & $24 \mathrm{~min}$ \\
\hline P7 & Sexual offences & 11 & $\mathrm{M}$ & & Mother $(\mathrm{P} 7 \mathrm{~b})$ & Detective Constable (P7a) & $\mathrm{F}$ & $56 \mathrm{~min}$ \\
\hline P8 & Sexual offences & 13 & $\mathrm{~F}$ & Autism & Mother (P8b) & Detective Constable (P8a) & $\mathrm{F}$ & $75 \mathrm{~min}$ \\
\hline P9 & Sexual offences & 20 & $\mathrm{~F}$ & Anxiety & No one & Detective Constable (P9a) & $\mathrm{F}$ & $35 \mathrm{~min}$ \\
\hline P10 & Sexual assault & 10 & $\mathrm{~F}$ & Autism & Mother (P10c); Intermediary (P10b); & $\begin{array}{l}\text { Detective Constable-Vulnerable } \\
\text { Investigation Team (P10a) }\end{array}$ & $\mathrm{F}$ & $25 \mathrm{~min}$ \\
\hline P11 & Rape & 27 & $\mathrm{~F}$ & $\begin{array}{l}\text { Learning } \\
\text { difficulties }\end{array}$ & Mother (P11b) & Detective Constable (P11a) & $\mathrm{F}$ & $65 \mathrm{~min}$ \\
\hline P12 & Rape of a child under 13 & 11 & $\mathrm{~F}$ & Autism & Mother (P12b) & $\begin{array}{l}\text { Detective Constable-Child } \\
\text { Protection (P12a) }\end{array}$ & $\mathrm{F}$ & $60 \mathrm{~min}$ \\
\hline P13 & Rape of a child under 13 & 13 & $\mathrm{~F}$ & Autism & Mother (P13c); Intermediary (P13b) & Detective Constable (P13a) & $\mathrm{F}$ & $180 \mathrm{~min}$ \\
\hline
\end{tabular}


Table 2. Overview of the themes, the number of cases where the themes appeared, and example interview quotes illustrating the themes.

\begin{tabular}{|c|c|c|}
\hline Theme & Number of Cases & Example Quote \\
\hline Change of focus for the survivor & $\mathrm{n}=13$ & $\begin{array}{l}\text { P7b: "He [the Facility Dog] really has changed the } \\
\text { whole focus for [the witness]. Before it was a scary } \\
\text { thing he couldn't do, but now, it's something he is } \\
\text { excited for." }\end{array}$ \\
\hline $\begin{array}{l}\text { A difference in the survivors' } \\
\text { engagement (Sub-themes: Change } \\
\text { in demeanour; Consenting to the } \\
\text { police interview; Enhanced } \\
\text { communication) }\end{array}$ & $\mathrm{n}=12$ & $\begin{array}{l}\text { P12a: "The interview went very well, she disclosed } \\
\text { and talked more than she had ever in the past. I've } \\
\text { been working as an interviewer for a few years and } \\
\text { never have I seen such a change in response about } \\
\text { attending an interview. When I met the individual in } \\
\text { the past, she seemed quite withdrawn and timid, but } \\
\text { with the dog she was so much more animated. } \\
\text { Whereas before she was dreading the interview, she } \\
\text { became almost excited about it now that [the Facility } \\
\text { Dog] was around." }\end{array}$ \\
\hline $\begin{array}{l}\text { The dog as a comforter to keep the } \\
\text { survivor calm }\end{array}$ & $\mathrm{n}=13$ & $\begin{array}{l}\text { P11: "[He] kept me completely calm. His whole } \\
\text { presence that he was there, it was so comforting. I } \\
\text { was holding his leash the whole time, I didn't even } \\
\text { need my own squishy toy. He was totally brilliant. I } \\
\text { am so happy he was here." }\end{array}$ \\
\hline Positive environment & $\mathrm{n}=10$ & $\begin{array}{l}\text { P5c: "This is not a child-friendly place, it's not an } \\
\text { inviting place for children. [The Facility Dog] makes } \\
\text { it inviting, I think, he makes it feel as though you're } \\
\text { not about to go into an interview." }\end{array}$ \\
\hline
\end{tabular}

\subsubsection{A Change in Focus for The Survivor}

One of the strongest themes across the cases was how the presence of the facility dog had changed the survivors' focus; re-framing what was otherwise an extremely upsetting day for them and providing them with something positive to focus on:

P11b: "This service is something which needs to be considered much more because now they can talk about the dog and they don't just have to talk about being at the police station. It completely changes your experiences."

P3b: "Before, she was so scared about coming here and then her focus just shifted to [the facility dog]: where he sleeps, what he eats, if he likes his job. And for me, that helped me know she was going to be okay."

Thus, knowing that there would be a dog at the police station that they could engage with provided the survivor with a positive distraction from the fear and anxiety they had about the day and gave them something positive to focus on rather than ruminating on the negative aspects of the day. In fact, some of the survivors had actually been looking forward to going to the police station so they could meet the dog:

P12b: "It's all she's talked about ... Even last night, she was talking about how excited she was."

P7a: "He has been so excited to meet [the dog]. We have been postponing his interview until we could use him. I'm glad we did. He was fantastic."

The survivors tended to side-step questions about how they felt about the interview itself, suggesting that they preferred not to think or talk about it, and the dog gave them something positive to focus on instead. For instance, when P13 was asked how her interview went, there was no mention of the interview itself. Instead, she said:

P13: "He fell asleep [laughs]. He loves his ears being stroked so much that he fell asleep on me [laughs]."

As well as providing a way for survivors to positively re-frame their thoughts about the interview, the dog also seemed to give them a way of coping when answering questions in the interview itself. As one survivor explained:

P1: "It helped during the interview, knowing he was there and that I could stroke him if it all got too much ... I was also looking forward to playing with him afterwards and not think about what I was talking about." 
With that, the dog also gave them something to focus on during moments of stress and distress, providing them with a coping mechanism to ameliorate some of the anxiety and distress they were feeling, as P7 explained:

P7: "I didn't need a break and I was scared I would. [The facility dog] is so warm and funny when he snores, he made me feel so much better. Made it easier than I thought."

Focusing on the dog during times of distress and anxiety was something which was frequently noted in the observations, too. For instance, P5 often looked at the dog during disclosures, tilting her head in such a way that only the dog was in her eye line. Similarly, P6, whose intermediary (P6b) said, "He usually goes from one thing to the next when we are talking but he just stayed focused ... he just sat staring at [the facility dog], did not lift his head or make eye contact at all during the interviews, instead fixating on the dog as he talked, stroking him and playing with his ears." P13 was also noted as avoiding eye contact with the interviewer, instead choosing to maintain focus on the dog and both she and a number of other participants (P1, P2, P7, P10, P13) were noted as increasing the intensity with which they petted the dog during their disclosures. It is likely that the presence of the dog enabled survivors to regain some control over proceedings which they otherwise have very little control over. Their ability to choose to focus on the dog who is only there to support them can be seen as crucial in their state management. The usefulness of the dog's presence during disclosures was something often commented on by the interviewing officers afterwards:

P11a: "The interview went really well. The person interviewed remained calm and was able to explain what happened. This was in large part because of [the facility dog]. In the past, we have struggled to get her to open up. The individual was smiling every time she looked down at [the facility dog] during the interview. It really changed how she perceived the process and has really helped her deal with everything. He really was a huge success. It also helped in the interview in a lot of ways."

So rather than their focus on the dog being a negative distraction during the interview, the survivors' focus on his presence actually enhanced their ability to verbally engage with the officers. As highlighted in the quote from officer P11a, above, this changed how the survivor responded to questioning and enabled more coherent disclosures. This was something which was felt by the officers from multiple cases and is discussed in more depth in the next theme.

\subsubsection{A Difference in the Survivors' Engagement}

Another frequently occurring theme across all of the cases was how differently the survivor felt and behaved when the dog was present compared to when he was not. The three main areas these changes were discussed in relation to were changes in: the survivors' demeanour, their willingness to be interviewed, and in the way they communicated during the interview.

\section{Changes in Demeanour}

As suggested by Figure 1, a physical change was often noticed upon the dog's arrival. For instance, P4 looked anxious and unhappy until the dog arrived and then, from that point onwards, she smiled almost continuously. Similarly, P11 initially looked very anxious and fidgety, repeatedly saying how nervous she was and appearing to struggle to control her breathing. As soon as the dog arrived, however, she ran over to hug him and once she had directed him onto the sofa next to her, she looked happy and relaxed. These differences in how the survivor looked and behaved reflected differences in how they described feeling when the dog was present. For instance, P13 explained:

P13: "He was so good. He just sat there with me and even started snoring which made us laugh. I didn't feel like I did before when I was interviewed, I just felt happy."

These changes were frequently commented on by the survivors' support, too, as the mother of one survivor said:

P11b: "She was so nervous in the parking lot, quite anxious, and then she saw [the facility dog] and, well, you saw it: she changed. I haven't seen her smile so much in ages. "

Similar words were also uttered by P2's mother: 
P2b: "Last time we were here, it took hours to even get her in the room. She was shaking and crying and she didn't want to do it. Now she just went straight into the room! I can't believe how happy she looks. She looks so different. And so much calmer."

Hence, the positive effect the dog had on the survivors' demeanour appeared to provide an emotional buffer for them, enabling them to do things they had previously been unwilling or unable to do, such as visiting the station or being interviewed.

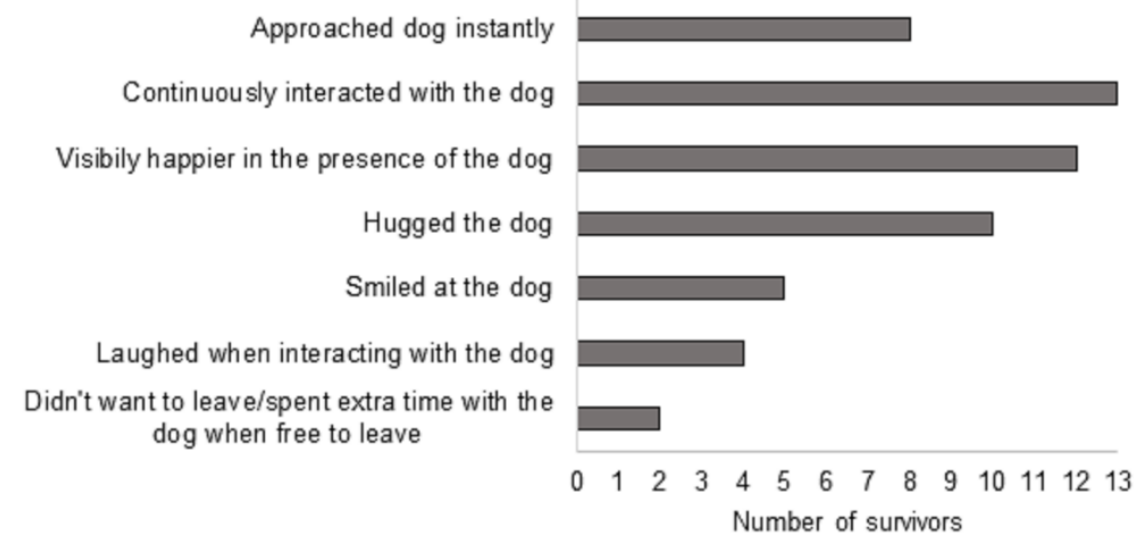

Figure 1. Observed behaviours exhibited by survivors upon initial introductions with the dog.

Consenting to the Police Interview

As the above quote from P2's mother (P2b) illustrates, several of the survivors' parents made reference to their children's previous reluctance to be interviewed and the usefulness of the dog in enabling them to engage with the interview process:

P6c: "I think it could really help a lot of victims, especially kids. I know mine wouldn't have been able to come without [the facility dog]."

This difference in the survivors' attitude to the interview was also something noticed by the officers conducting the interview:

P7a: "Was able to build a really good rapport with the child because of [the facility dog] ... [the facility dog] cuddled with him and he said it made him feel more confident and excited to come in. Which he refused to do in the past."

Thus, because the dog made the survivor more willing to come to the police station, and because the survivors were therefore in less of an agitated state, it then made it easier for the officers to build a rapport with the witness and increase the quality of the information they could obtain from them. Whilst coming into a police interview is a clear goal of a criminal investigation, it is not always the case that this is the right action for survivors as per kaleidoscopic justice principles. However, in these cases, it is key to appreciate that the survivors wanted to engage, but often felt too uneasy to do so. By enabling them to continue in their justice journey without further traumatising them, the outcomes that the police and survivors desire can become more closely aligned.

\section{Enhanced Communication}

The interviewing officers often made reference to how much more fluid and coherent the survivors were when they were talking and how much more willing the survivors were to talk about the more distressing details:

P5a: "I would happily use [the facility dog] again as I felt he gave this child the confidence in order to speak up, as until the $\mathrm{ABE}$, she would only write what was done to her but in the $\mathrm{ABE}$, with the assistance of [the facility dog], she spoke and gave disclosure."

The consensus seemed to be that the dog acted as a source of comfort for the survivor, allowing them to keep calm and tell the officers what happened to them: 
P11a: "The interview went very well. The individual opened up for the first time and was calm and communicated clearly. The dog made a huge difference and made this a positive experience for the individual. He kept her calm when she is normally very anxious and unable to talk about the offence."

Again, reference is made to the dog turning the interview into a positive experience for the survivor and this notion of the dog as a comforter, enabling them to remain calm, was the strongest and most commonly occurring theme present in the qualitative data from all cases. Whilst communicating about distressing details seemed to be enhanced, this does not mean it was still not difficult for the survivors. However, as they were able to refocus their attention to the dog, as visible above, under Section 3.2.1 and below, under Section 3.2.3, the negative impact of such disclosure can be seen to be mitigated.

\subsubsection{The Dog as a Comforter to Calm the Survivor}

The reassurance that the survivors got from the dog was repeatedly noted in the observations. Survivors such as P12 would only go near the interview suite once the dog arrived and some of the survivors made repeated checks to ensure the dog would not be taken away, indicating the importance of his presence for them and implying that he was acting as a much needed source of comfort. For instance, P11 asked, "I'm glad he is here, he can stay right?", similarly, P4 repeatedly said, "He can come in with me, right?". Additionally, some survivors kept tight hold of his lead when they were with him, even whilst playing with him, reflecting a need to ensure that he stayed with them and to maintain a sense of control over their environment, which has been described by survivors in other studies as an environment where they do not feel to be in control at all:

P11: "I was calm the whole time because I was with him and I could have his lead and he was with me all the time. I took him to see the rooms and he was with me the whole time."

The repetition of the dog being with her "the whole time" suggests the importance of that to her, again indicating how much comfort she was drawing from having him by her side and being able to have some control over the situation. This was something which was often noticeable in other survivors' speech, too:

P2: "It was really good. He was really good. He was going everywhere with me and he came to the room with me. It was fun to be with him and he is so cuddly. I could hug him and he was waiting for me when I was done to hug him."

Hugging the dog appeared to be an important source of comfort for several of the survivors, as P4 described, "He was really cuddly and warm which was nice. And he stayed so close to me the whole time." Several of the other survivors also mentioned his warmth: "His body heat is quite comforting" (P11), which suggests that they drew comfort from his body heat and implies that the close proximity of his body provided them with reassurance, as P12 explained: "He definitely helped! He just sat with me, it was really nice. And he sat so close to me the whole time." P10's intermediary (P10b) further noted how this is something which is "hard to achieve through any other method out there." The uniqueness of what a facility dog can provide during their police interview in terms of comfort is particularly highlighted in the following quote from one survivor:

P8: "I could feel his snoring on my leg. It was strangely nice and soothing. He was just so relaxed with me. Like he trusted me enough to sit on me and fall asleep. His presence just made me feel better."

The dog's specialist training meant that he was an active participant in providing comfort to the survivors in times of stress and distress, as noted by one of the interviewing officers: "He could really sense when she was upset. I noticed when she was disclosing, it's like he knew. Every time, he inched closer to her body" (P11a). This was something which did not go unnoticed even by the child survivors:

P7: "He stood up when I got upset and put his head on my leg. When I got more upset he tried to get even closer [laughs]."

An 11-year-old child, laughing when talking about how distressed he was during a disclosure suggests a more positive reframing, with the dog's behaviour enabling him to have a positive memory 
to associate with the incident. The ability of the dog to calm the survivors' emotions and, therefore, reduce the potential trauma of the interview itself was repeatedly noted by officers:

P1a: "I felt that he was amazing. Not only did he allow the victim to give a very good ABE, but he kept her calm and suppressed her anxiety."

The dog's calming effect was not just on the survivors, but also reported by their families, as one mother said:

P10c: "Even I could feel his calmness. I was shaking before and now I just feel so much better. It's incredible."

Arguably, the more at ease the survivors' supports feel, the better it is for the survivor, and this knock-on effect of the dog's presence on the atmosphere as a whole is the focus of the final theme.

\subsubsection{Positive Environment}

Although the dog's main purpose was to provide support for the survivor, as mentioned above, he also had a calming effect on their support, too, and knowing that he was there for the survivor provided an additional form of comfort for the support:

P10c: "I didn't want her going in there all alone and scared. I know she has people with her but knowing that [the facility dog] is there just for her, it really helps me feel better as well ... She barely talks since all this happened. I just know [the facility dog] will help her feel safe. She worries about that a lot."

The suggestion that the dog's presence would provide the survivor with a feeling of safety was confirmed by one of the survivors:

P5: "I would recommend [the facility dog] for children; he made me safe and happy."

Part of this feeling of safety was likely due to the observation made by some of the support that having a dog present makes "the process less intimidating for people" (e.g., P12b). Even the officers who are used to working in the ABE suites and were therefore more at ease in that environment than the visitors, commented on how different the atmosphere felt with the dog there:

P7a: "[The facility dog] ... really broke the tension and made everything less clinical and much more personal."

P5a: "It was a pleasant experience for the child. She had a really lovely experience and [the facility dog] was really helpful, creating a positive atmosphere."

P10a: "He made everything feel much more relaxed, which is really important during an ABE."

The notion that the dog's presence made for a positive atmosphere and, thereby, a nicer environment was something which was brought up repeatedly by those used to dealing with vulnerable people. One interviewing officer said:

P4a: "It is an amazing service and it was visible that [the facility dog] made the environment more positive and enabled the victim to be calmer."

The positive effect, already discussed in previous themes, that the dog had on the survivors' demeanour and also to how their support were feeling would have helped with this, but beyond that, there was a consensus that the dog's presence reduced the formality and made everyone feel at ease more generally:

P5a: "Every single person who came into the $\mathrm{ABE}$ area and stroked the dog left with a smile on their face. I think Kent Police should have a "bring your dog to work day" and then we would all be happy."

P10b: "I just think it helps all round. He lightens the mood and you can't help but smile at that face."

\subsubsection{Summary}

In sum, the qualitative data, which were supported above by the observational data, suggest that the facility dog enhanced the survivors' willingness to discuss what had happened to them and their ability do so coherently. This was partly due to creating a more relaxed, less intimidating environment, 
and largely to do with his comforting presence, which in turn helped to calm the survivors, thereby producing observable differences in the survivors' demeanour and providing them with something positive to focus on, while also allowing them to reframe a potentially traumatising ordeal into a more positive experience.

It was encouraging to see that the officers placed much importance on a comfortable environment for the survivors in their comments relating to the service. As noted in the literature review, the police may have different outcomes in mind in terms of the aims of a video-recorded interview. Throughout this study, whilst commenting on quality evidence, they commented on the way the dog enabled better state management and communication, in line with survivors' perspectives of what justice may look like. Whilst it is not suggested here that police officers do not have disclosure in mind, their focus on survivor well-being was present throughout.

It should also be highlighted that the dog himself was not observed as showing any signs of stress or distress during his time with any of the survivors, and was so comfortable during three of the cases, that he fell asleep cuddled up next to the survivor (P7, P9 and P10), something which each of them seemed delighted by. It was also noted, by both the observers and the officers, that the dog did not act as a negative distraction during any of the cases.

\subsection{Survey Data}

The themes generated above were further supported by the survey data collected from the interviewing officers and survivors. When interviewing officers were asked why they requested the facility dog, the most common reason given was because they believed the dog's presence would have a calming effect on the survivor $(n=10)$. The term 'calm' was sometimes meant in terms of soothing fears and anxieties the officers had previously witnessed in their prior encounters with the survivor, and was sometimes meant with regards to trying to keep the survivor still for long enough to interview (e.g., due to problems with attention or hyperactivity). Almost as commonly cited was the belief that the dog's presence would help the survivor open up/communicate $(n=9)$ and the hope that the service would alter the survivor's focus $(n=7)$ (either in terms of giving them something positive to focus on $(n=5)$ or helping them to concentrate on the interview $(n=2))$.

When the survivors were surveyed before meeting the facility dog and asked how they were feeling about their upcoming video-recorded interview and how they felt knowing that the dog would be there, most $(n=10)$ did not directly address the question about the interview, instead focusing their answers on the question about the dog. As can be seen from Figure 2, the survivors' answers about the dog were all positive and were either framed as eliciting positive feelings (e.g., excited, happy, supported) or as reducing negative feelings (e.g., less anxious, less scared).

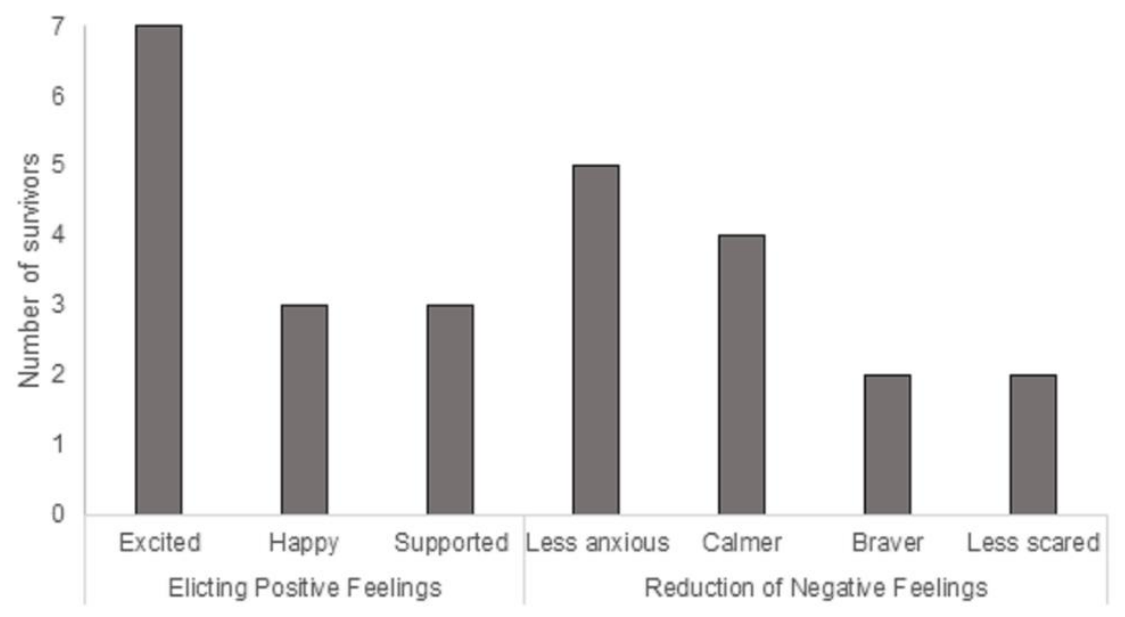

Figure 2. Survivors' feelings relating to the presence of the facility dog. 
Of the survivors who did refer to their feelings about the interview directly $(\mathrm{n}=3)$, one admitted to being "very scared" (P11), one said they were "really nervous" (P10), and one said they were "very stressed about the interview, very uncomfortable" because they did not "like talking about [what happened]" (P3). However, even those who only talked about the dog gave answers which suggested that the thought of the interview was upsetting for them; which was likely why they chose not to answer that part of the question directly. For example, P12 said that she thought the dog would "make me brave enough to talk" and both P5 and P10 said they thought that having a dog sitting with them would "help me get through the interview." So it was clear, even for those who did not directly answer the question about the interview specifically, that they were scared and/or anxious and viewed it as another ordeal to get through. This was also supported by the survivors' anxiety scores.

In their survey beforehand, survivors were asked to fill out a 10-item anxiety scale. The range of possible scores is 20-80 with higher scores representing higher levels of anxiety. Before meeting the facility dog, the survivors' anxiety about their upcoming police interview ranged from 26 to 80 with a mean anxiety score of $55.1(\mathrm{SD}=15.4)$. After spending some time with the dog, the anxiety ranged from 20-68 with a mean anxiety score of $39.2(S D=13.8)$. This represents a significant drop in anxiety, $t(12)=7.850, p<0.001, d=1.09$ (see Figure 3 ).

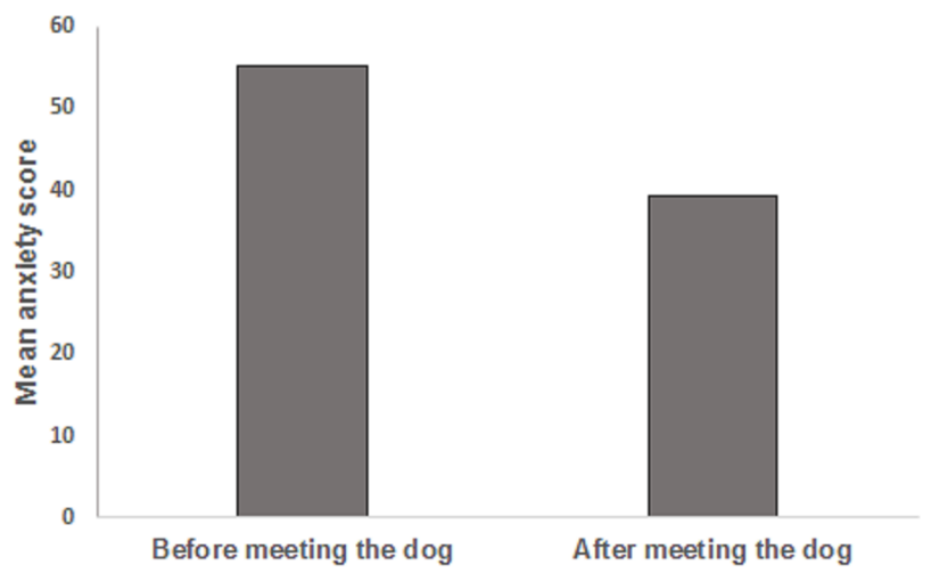

Figure 3. Survivors' anxiety about their upcoming police interview, before and after engaging with the facility dog. Higher scores indicate greater anxiety.

\section{Discussion}

This study set out to investigate the support that facility dogs can provide survivors of sexual crimes when undergoing a video-recorded interview. The multiple case study was guided by two core research questions: (1) What is the perceived impact of a facility dog by those directly involved with a specific case? and (2) What changes can be observed in survivors' behaviour and state management through the introduction of this service? Overall, the findings suggest that the facility dog provided a much needed and beneficial service to survivors, helping them feel calmer and more comfortable, both prior to the interview and during. The dog also provided survivors with a more positive environment, allowing them to focus on the interview and communicate more openly about their experiences. Participants consistently reported that the facility dog helped to reduce the fear of the interview process, providing them with something positive to focus on. It was also noted by several participants how the comforting presence of the dog created an environment that better enabled the survivor to engage within the interview. While the benefits of the facility dog were highlighted by participants in various ways and to different degrees, the overall findings are consistent with previous anecdotal evidence which emphasises the benefits that facility dogs provide victims in the CJS (e.g., Dellinger 2009; Sandoval 2010; Weems 2013). The results also add to the findings from the one other study, conducted in the USA, which investigated the presence of a facility dog during a police interview with children. Krause-Parello et al. (2018) found that when a facility dog was present, 
a child's stress significantly decreased after their police interview. Here, we found evidence of even wider benefits. The findings further support the more general body of evidence showing that dogs help to alleviate stress for people when under duress (Crenshaw 2011) and make them feel more calm and relaxed (McNicholas and Collis 2006), as well as more in control of the processes.

Along with the emotional support provided, the survivors also perceived the facility dog to create a more positive and comfortable environment. Research has continually emphasised the detached and intimidating nature of the investigation process (Beckett and Warrington 2015), particularly for young survivors of sexual crimes who often express dissatisfaction with the CJS due to the uncaring and impersonal processes (Marsh et al. 2019). The importance of providing survivors with a relaxed and comfortable environment, where they feel safe and supported, has been a key message in recent evidence reviews on policing and safeguarding (Allnock 2015). The current study, therefore, found support for a novel and innovative way to help the criminal justice environment become more victim-survivor friendly and comfortable, a key objective of the Victim's Strategy (HM Government 2018) and an important part of the interview process (Ministry of Justice et al. 2013). Survivors were able to physically interact with the dog on a personal level (e.g., touching, cuddling), an interaction that many survivors are not comfortable doing with others, or are not allowed to do with individuals in official supportive capacities. It could therefore be suggested that this interaction enabled an environment that allowed them to re-anchor their thoughts in a constructive light, mitigating the negative connotations that often surround the legal process. This had a positive effect on the survivors' general demeanour and motivation towards the interview, allowing them to focus on the task at hand-the interview. The benefits shown could also help to alleviate the secondary victimisation that many victims experience as a result of the CJS processes, as an important pathway between victimization and emotional recovery is the way victims feel they are treated within the CJS (Elliott et al. 2013; Parsons and Bergin 2010).

The emotional and environmental benefits that the facility dog provided further influenced the credibility of the survivors, as it allowed them a pathway to better communication. Research on witness credibility suggests that maintaining a relaxed state with clear and fluent communication are key indicators of credibility (Boccaccini and Brodsky 2002). Results from the current study showed a decrease in anxiety when the facility dog was present and an increase in overall comfort for the survivor, helping to mitigate the heightened levels of fear and anxiety that are often associated with the traumatic experiences of sexual crimes (e.g., Campbell and Wasco 2005), enabling them to communicate more clearly within their police interview. Previous research has shown that victims-survivors are able to communicate more effectively when their emotional well-being is protected (O'Mahony et al. 2016). With that, Bowers (2013) contended that lawyers across North America have been encouraging the use of facility dogs, as they help individuals to communicate with more ease. Similarly, Spruin et al. (2019a) suggested that such a service can be useful in allowing survivors of sexual crimes to feel less anxious and more confident prior to giving evidence. The current study, therefore, provides strong grounding to utilising facility dogs as an aid to communication. Under Section 30 (s.30) of the Youth Justice and Criminal Evidence Act (1999), aids to communication may be permitted to enable a witness to give best evidence; this can be through a communicator, or through a communication aid or technique. The findings that interviewing officers commented on the impact of the facility dog on state management as a facilitator to better communication is also key here. As the police can be target-driven in terms of obtaining disclosure, the officers' focus on state management as the key factor, rather than disclosure, shows an approach more in line with a survivor's perceptions of justice.

Overall, the findings not only provide evidence for the benefits that facility dogs can have in supporting survivors of sexual crimes, but they also highlight the impact these dogs could have on current practices and policies within the CJS. In particular, facility dogs have the potential to provide survivor-focused support throughout the whole criminal justice process, thereby providing an experience that is not only less traumatic and intimidating, but also one that is emotionally supportive and comforting. This is something that is currently lacking within the CJS; it is a process that needs to 
be more personal, where victims-survivors do not feel like they are accessories to the system, but rather contributors to justice (Payne 2009). The current findings have thus provided the first step toward developing an initiative that has the potential to radically progress and modernize the services currently available to victims. The cornerstone to this initiative lies within the unique ability that dogs have in terms of supporting humans. The evolutionary bond that has existed between humans and canines has been built over thousands of years of evolution (Coppinger and Coppinger 2001), which has had a significant effect on our genetic makeup (Persson et al. 2017). As a result, dogs naturally play a role in facilitating trust and attachment (Yang et al. 2013), they also naturally aid in the reduction of fear, anxiety and other negative moods (Guzmán et al. 2013), providing a number of emotional benefits that surpass those of any other animal and even humans. In fact, research shows that dogs can create an instant bond with a person and elicit immediate comfort, similar to the bonds created by mothers and their newborn infants (Odendaal and Meintjes 2003). The power of this relationship was also shown in the current study, where all survivors noted positive effects immediately upon interacting with the facility dog.

Through feelings of being supported and comfortable, being in a more favourable environment, and being able to give evidence in a more credible manner, the use of facility dogs can bring us one step closer to bridging the existing justice gap for survivors of sexual offending. Being able to have a voice and being treated with dignity and fairness all relate to kaleidoscopic justice (McGlynn and Westmarland 2018). The current findings strongly show that participants felt more positive on a number of different factors relating to their experiences, perceiving their journey in a different light, hence increasing their perceptions of justice. This is important for all criminal justice agencies. Specifically, as the focus of this study was on police interviewing (via video-recorded interview), embedding a service like this into police practice would enable one part of the Policing Vision 2025 (National Police Chiefs' Council 2016), relating to effective and better caring for victims, to come to fruition.

Although this research provides a strong argument for the introduction of facility dogs into the CJS, there are limitations to consider. A common critique of a case study design lies in its small sample size. Whilst it was not the intention of this research to provide generalizable findings, due to the depth provided, we believe that naturalistic generalisation (Stake 1995) can be achieved. With that, the design was further intended to give survivors, and their support, a chance to give feedback on their experiences. The government has introduced a range of initiatives and policies to improve the experiences of victims. Likewise, academics have continued to debate the needs and rights of these individuals. However, what has been consistently missing throughout all these provisions is the voice of the victim. A fundamental part to understanding the needs of victims is to listen to their perceptions of the support they receive (Victims' Commissioner 2016). Part of meeting the needs of victims is to give them a voice where they can express their experiences, thoughts and desires (Bottoms and Roberts 2010; McGlynn and Westmarland 2018). The current study, therefore, incorporated this voice into the research, in order to ensure a victim-focused viewpoint. That being said, it is key to conduct further and larger research as a way of elaborating on the present results, as this study took place in conjunction with one police force, therefore, the survivors involved were from a specific jurisdiction-South-East England. Survivors may have different experiences based on provisions provided in different parts of the country. With that, a single ADI-accredited facility dog was used, and while all facility dogs must adhere to the same ADI standards, future research should explore ways of including more facility dogs from other countries, and also sustainable ways of training more ADI-facility dogs within the UK. Lastly, as has been noted throughout, it is key to further explore the way the facility dog can impact on perceived justice based on the different actors involved (i.e., survivors versus police officers); such comparisons could not be made here due to the design and study aims. However, future research should thoroughly explore how the use of facility dogs aligns with the desired outcomes of the different parties involved. For example, enhanced disclosure may not always be preferred to survivors, though it is preferred to the police. 
This study set out to evaluate the support that facility dogs can provide to survivors of sexual crimes within police interviews. It was the first study, globally, to incorporate the perception of the survivor within the evaluation, thus providing an in-depth understanding into the experiences of vulnerable survivors and the support that facility dogs can provide. It was also the first study in the UK, and Europe, to explore the use of facility dogs within the CJS and the possible benefits these dogs could have throughout the criminal justice process.

The results identified a much needed service, which provided a number of benefits to the survivors that utilised the facility dog, including: helping them feel calmer and more comfortable, providing a positive environment, and allowing them to focus on the interview. The impact of these benefits were further reflected in the physical changes (e.g., smiling, stopping crying, looking happier, laughing, etc.) of the survivors and also their shift in focus towards the interview process. The current study, therefore, presents very positive findings relating to the impact of facility dogs on survivors of sexual crimes and bridging their justice gap; however, due to its design and inherent limitations, it is highly recommended that future research is conducted to explore the service further. Nevertheless, it is recommended that the CJS in England and Wales explore the use of this service with police interviews, with potential to expand the use of these dogs to other areas of the CJS. Due to the success of this pilot evaluation, as noted by not only practitioners but also survivors themselves, a number of police services in England have already included the exploration of this service in their agenda of improving survivor experiences, and we are confident that such initiatives should continue.

Author Contributions: Conceptualization, E.S. and K.M.; methodology, E.S. and K.M.; software, N/A; validation, E.S. and K.M.; formal analysis, T.D.; investigation, E.S. and K.M.; resources, E.S., K.M., and R.F.; data curation, E.S., K.M., and R.F.; writing-original draft preparation, E.S., K.M., and T.D.; writing—review and editing, E.S., K.M., and T.D.; visualization, E.S., K.M., and T.D.; supervision, E.S. and K.M.; project administration, E.S. and K.M.; funding acquisition, N/A. All authors have read and agreed to the published version of the manuscript.

Funding: This research received no external funding.

Acknowledgments: The authors are grateful to Duo Dogs, Kent Police, and the interviewing officers for their contribution to the project. We would also like to acknowledge and thank both Duo Dogs and Kent Police for their ongoing support for the research project.

Conflicts of Interest: The authors declare no conflict of interest.

\section{References}

Allnock, Debra. 2015. What Do We Know about Child Sexual Abuse and Policing in England and Wales? Evidence Briefing for the National Policing Lead for Child Protection and Abuse Investigation. Luton: University of Bedfordshire, International Centre.

Antaki, Charles, Emma Richardson, Elizabeth Stokoe, and Sara Willott. 2015. Police interviews with vulnerable people alleging sexual assault: Probing inconsistency and questioning conduct. Journal of Sociolinguistics 3: 328-50. [CrossRef]

Barker, Sandra B., Randolph T. Barker, Nancy L. McCain, and Christine M. Schubert. 2016. A randomized crossover exploratory study of the effect of visiting therapy dogs on college student stress before final exams. Anthrozoos 29: 35-46. [CrossRef]

Baverstock, John. 2017. Process Evaluation of Pre-Recorded Cross Examination Pilot. London: Home Office.

Beckett, Helen, and Camille Warrington. 2015. Making Justice Work. Bedford: University of Bedfordshire.

Boccaccini, Marcus T., and Stanley L. Brodsky. 2002. Believability of expert and lay witnesses: Implications for trial consultation. Professional Psychology: Research and Practice 33: 384-88. [CrossRef]

Bottoms, Anthony, and Julian V. Roberts. 2010. Hearing the Victim: Adversarial Justice, Crime Victims, and the State. Cullompton: Willan Publishing.

Bowers, Sarah V. 2013. The use of therapy dogs in Indiana courtrooms: Why a dog might not be a defendant's best friend. Indiana Law Review 46: 1289-2013.

Braun, Virginia, and Victoria Clarke. 2006. Using thematic analysis in psychology. Qualitative Research in Psychology 3: 77-101. [CrossRef] 
Brooks, Oona, and Michele Burman. 2017. Reporting rape: Victim perspectives on advocacy support in the criminal justice process. Criminology and Criminal Justice 3: 1-27. [CrossRef]

Brown, Jennifer. 2011. We mind and we care but have things changed? Assessment of progress in reporting, investigating and prosecution of rape. Journal of Sexual Aggression 17: 263-72. [CrossRef]

Burman, Michele. 2009. Evidencing sexual assault: Women in the witness box. Probation Journal 56: $379-98$. [CrossRef]

Campbell, Rebecca, and Sharon M. Wasco. 2005. Understanding rape and sexual assault: 20 years of progress and future directions. Journal of Interpersonal Violence 20: 127-31. [CrossRef]

Chandler, Cynthia K. 2012. Animal Assisted Therapy in Counseling. New York: Routledge.

Children's Commissioner. 2015. Protecting Children from Harm: A Critical Assessment of Child Sexual Abuse in the Family Network in England and Priorities for Action. London: Children's Commissioner for England.

Coppinger, Roy, and Lorna Coppinger. 2001. Dogs: A Startling New Understanding of Canine Origin, Behavior and Evolution. New York: Scribne.

Courthouse Dogs Foundation. 2019. Facility Dogs: Where Are They Working? Available online: https: //courthousedogs.org/dogs/facility-dogs/ (accessed on 20 May 2020).

Crenshaw, David A. 2011. The play therapist as advocate for children in the court system. Play Therapy 6: 6-9.

Creswell, John W. 2007. Qualitative Inquiry \& Research Design: Choosing among Five Approaches. Thousand Oaks: Sage Publications.

Daly, Beth, and L. L. Morton. 2006. An investigation of human-animal interactions and empathy as related to pet preference, ownership, attachment, and attitudes in children. Anthrozoos 19: 113-27. [CrossRef]

Damon, Joanne, and Rita May. 1986. The effects of pet facilitative therapy on patients and staff in an adult day care centre. Activities, Adaptation and Aging 8: 117-31.

Deffenbacher, Kenneth A., Brian H. Bornstein, Steven D. Penrod, and E. Kiernan McGorty. 2004. A meta-analytic review of the effects of high stress on eyewitness memory. Law and Human Behaviour 28: 687-706. [CrossRef] [PubMed]

Dellinger, Marianne. 2009. Using dogs for emotional support of testifying victims of crime. Animal Law 15: 171-92.

Elliott, Irina, Stuart Thomas, and James Ogloff. 2013. Procedural justice in victim-police interactions and victims' recovery from victimisation experiences. Policing and Society 24: 588-601. [CrossRef]

European Parliament and Council. 2012. Directive 2012/29/EU of the European Parliament and of the council establishing minimum standards on the rights, support and protection of victims of crime. Official Journal of the European Union 315: 57-73.

Gibbs, Graham R. 2002. Qualitative Data Analysis: Explorations with NVivo. Buckingham: Open University Press.

Grace, Sharon, Charles Lloyd, and Lorna J. F. Smith. 1992. Rape: From Recording to Conviction. London: Home Office Research Unit.

Greene, Sheila, and Diane Hogan. 2005. Researching Children's Experience: Approaches and Methods. London: Sage Publications.

Gregory, Jeanne, and Sue Lees. 1999. Policing Sexual Assault. London: Routledge.

Guzmán, Yomayra F., Natalie C. Tronson, Vladimir Jovasevic, Keisuke Sato, Anita L. Guedea, Hiroaki Mizukami, Katsuhiko Nishimori, and Jelena Radulovic. 2013. Fear-enhancing effects of septal oxytocin. Nature Neuroscience 16: 1185-87. [CrossRef]

Halligan, Sarah L., Tanja Michael, David M. Clark, and Anke Ehlers. 2003. Posttraumatic stress disorder following assault: The role of cognitive processing, trauma memory, and appraisals. Journal of Consulting and Clinical Psychology 71: 419-31. [CrossRef]

Hamlyn, Becky, Andrew Phelps, and Ghazala Sattar. 2004a. Key Findings from the Surveys of Vulnerable and Intimidated Witnesses 2000/01 and 2003; Home Office Research Findings 240; London: Home Office.

Hamlyn, Becky, Andrew Phelps, and Ghazala Sattar. 2004b. Are Special Measures Working? Evidence from Surveys of Vulnerable and Intimidated Witnesses; Home Office Research Study 283; London: Home Office.

Hanway, Pamela, and Lucy Akehurst. 2018. Voices from the front line: Police officers' perceptions of real-world interviewing with vulnerable witnesses. Investigative Interviewing: Research and Practice 9: 14-33.

Hester, Marianne. 2013. From Report to Court: Rape Cases and the Criminal Justice System in the North East. Bristol: University of Bristol in association with the Northern Rock Foundation.

Hill, Emily S., and Graham M. Davies. 2012. Has the quality of investigative interviews with children improved with changes in guidance? An exploratory study. Policing: A Journal of Policy and Practice 7: 63-71. [CrossRef] 
HM Government. 2018. Victims Strategy. Available online: https://www.gov.uk/government/publications/victimsstrategy (accessed on 20 May 2020).

HMIC/HMCPSI. 2012. Forging the Links: Rape Investigation and Prosecution. A Joint Review by HMIC and HMCPSI. London: TSO.

Hohl, Katrin, and Elisabeth A. Stanko. 2015. Complaints of rape and the criminal justice system: Fresh evidence on the attrition problem in England and Wales. European Journal of Criminology 12: 324-41. [CrossRef]

Home Office. 2004. Are Special Measures Working? Evidence from Surveys of Vulnerable and Intimidated Witnesses. London: Home Office Research Studies.

Home Office. 2006. An Evaluation of the Use of Special Measures for Vulnerable and Intimidated Witnesses. London: Home Office Research Studies.

Ishak, Noriah Mohd, and Abu Bakar. 2013. Developing sampling frame for case study: Challenges and conditions. World Journal of Education 4: 29.

Jordan, Jan. 2011. Here we go round the review-go-round: Rape investigation and prosecution- are things getting worse not better? Journal of Sexual Aggression 17: 234-49. [CrossRef]

Kelly, Liz, Jo Lovett, and Linda Regan. 2005. A Gap or Chasm? Attrition in Reported Rape Cases. London: Home Office Research Study, vol. 293.

Konradi, Amanda. 1999. "I don't have to be afraid of you": Rape survivors' emotion management in court. Symbolic Interaction 22: 45-77. [CrossRef]

Krause-Parello, Cheryl A., Michele Thames, Colleen M. Ray, and John Kolassa. 2018. Examining the effects of a service-trained facility dog on stress in children undergoing forensic interview for allegations of child sexual abuse. Journal of Child. Sexual Abuse 27: 305-20. [CrossRef]

Lea, Susan J., Ursula Lanvers, and Steve Shaw. 2003. Attrition in rape cases: Developing a profile and identifying relevant factors. British Journal of Criminology 43: 583-99. [CrossRef]

Leedy, Paul D., and Jeanne E. Ormrod. 2001. Practical Research: Planning and Design, 7th ed. Upper Saddle River: Merrill Prentice Hall.

Maguire, Mike, Rod Morgan, and Robert Reiner. 2007. The Oxford Handbook of Criminology. Oxford: OUP.

Maier, Shana L. 2008. "I have heard horrible stories ... ": Rape victim advocates' perceptions of the re-victimization of rape victims by the police and medical system. Violence Against Women 14: 786-808. [CrossRef]

Majić, Tomislav, Hans Gutzmann, Andreas Heinz, Undine E. Lang, and Michael A. Rapp. 2013. Animal-assisted therapy and agitation and depression in nursing home residents with dementia: A matched case-control trial. American Journal of Geriatric Psychiatry 21: 1052-59. [CrossRef]

Marsh, Nicola, Emma McKay, Clara Pelly, and Simon Cereda. 2019. Public Knowledge of and Confidence in the Criminal Justice System and Sentencing. London: Sentencing Council.

Marteau, Theresa M., and Hilary Bekker. 1992. The development of a six-item short-form of the state scale of the Spielberger State-Trait Anxiety Inventory (STAI). British Journal of Clinical Psychology 31: 301-06. [CrossRef]

Maxwell, Joseph A. 2012. Qualitative Research Design: An Interactive Approach. Thousand Oaks: Sage, vol. 41.

McEwan, Jenny. 1990. In the box or on the box? The Pigot Report and child witnesses. Criminal Law Review, 363-70.

McEwan, Jenny. 2005. Proving consent in sexual cases: Legislative change and cultural evolution. International Journal of Evidence and Proof 9: 1-28. [CrossRef]

McGlynn, Clare, and Nicole Westmarland. 2018. Kaleidoscopic Justice: Sexual violence and victim-survivors' perceptions of justice. Social and Legal Studies 28: 179-201. [CrossRef]

McGlynn, Clare, Julia Downes, and Nicole Westmarland. 2016. Seeking justice for survivors of sexual violence: Recognition, voice, and consequences. In Sexual Violence and Restorative Justice: Legal, Social and Therapeutic Dimensions. Edited by Estelle Zinsstag and Marie Keenan. London: Routledge, pp. 179-91.

McMillan, Lesley. 2014. The role of the specially trained officer in rape and sexual offence cases. Policing and Society 4: 8-23. [CrossRef]

McNicholas, June, and Glyn M. Collis. 2006. Animals as social supports: Insights for understanding animal-assisted therapy. In Handbook on Animal Assisted Therapy. Edited by Aubrey H. Fine. San Diego: Elsevier, pp. 49-71.

Ministry of Justice. 2012. Getting It Right for Victims and Witnesses. Available online: https://www.gov.uk/ government/publications/getting-it-right-for-victims-and-witnesses (accessed on 20 May 2020).

Ministry of Justice, Home Office, and The Office for National Statistics. 2013. An Overview of Sexual Offending in England and Wales. London: Official Statistics Bulletin. 
Mulcahy, Linda. 2010. Legal Architecture: Justice, Due Process and the Place of Law. London: Routledge.

National Police Chiefs' Council. 2016. Policing Vision 2025. Available online: https://www.npcc.police.uk/ documents/Policing\%20Vision.pdf (accessed on 20 May 2020).

O'Haire, Marguerite E. 2013. Animal-assisted intervention for autism spectrum disorder: A systematic literature review. Journal of Autism and Developmental Disorders 43: 1606-22. [CrossRef] [PubMed]

O'Mahony, Brendan M., Jane Creaton, Kevin Smith, and Rebecca Milne. 2016. Developing a professional identity in a new work environment: The views of defendant intermediaries working in the criminal courts. Journal of Forensic Practice 18: 155-66. [CrossRef]

Odendaal, Johannes S. J., and Roy Alec Meintjes. 2003. Neurophysiological correlates of affiliative behaviour between humans and dogs. The Veterinary Journal 165: 296-301. [CrossRef]

Office for National Statistics. 2013. An Overview of Sexual Offending in England and Wales. London: Office for National Statistics.

Office for National Statistics. 2018. Sexual Offending: Victimisation and the Path through the Criminal Justice System. London: Office for National Statistics.

Office for National Statistics. 2019. Crime in England and Wales: Year Ending June 2019. Available online: https:/www.ons.gov.uk/peoplepopulationandcommunity/crimeandjustice/bulletins/ crimeinenglandandwales/yearendingjune2019 (accessed on 20 May 2020).

Oliver-Hoyo, Maria, and DeeDee Allen. 2006. The use of triangulation methods in qualitative educational research. Journal of College Science Teaching 1: 42-47.

Parsons, Jim, and Tiffany Bergin. 2010. The impact of criminal justice involvement on victims' mental health. Journal of Traumatic Stress 23: 182-88. [CrossRef]

Patton, Michael Q. 1990. Qualitative Evaluation and Research Methods, 2nd ed. Newbury Park: Sage.

Payne, Sara. 2009. Redefining Justice: Addressing the Individual Needs of Victims and Witnesses. London: Ministry of Justice.

Persson, Mia E., Agaia J. Trottier, Johan Bélteky, Lina S. V. Roth, and Per Jensen. 2017. Intranasal oxytocin and a polymorphism in the oxytocin receptor gene are associated with human-directed social behavior in golden retriever dogs. Hormones and Behavior 95: 85-93. [CrossRef]

Quas, Jodi A., and Gail S. Goodman. 2012. Consequences of criminal court involvement for child victims. Psychology Public Policy, and Law 18: 392. [CrossRef]

Rape Crisis Network. 2018. Hearing Every Voice-Towards a New Strategy on Vulnerable Witnesses in Legal Proceedings. Ireland: Dublin.

Sanders, Clinton R. 2003. Actions speak louder than words: Close relationships between humans and nonhuman animals. Symbolic Interaction 26: 405-25. [CrossRef]

Sandoval, Gabriela N. 2010. Court Facility Dogs_Easing the apprehensive witness. Colorado Lawyer 39: 17.

Schuck, Sabrina E. B., Natasha A. Emmerson, Aubrey H. Fine, and Kimberley D. Lakes. 2013. Canine-assisted therapy for children with ADHD: Preliminary findings from the positive assertive cooperative kids study. Journal of Attention Disorders 19: 125-37. [CrossRef]

Silverman, David. 2013. Doing Qualitative Research: A Practical Handbook, 4th ed. London: Sage.

Spruin, Elizabeth, and Katarina Mozova. 2018. Dogs in the criminal justice system: Consideration of facility and therapy dogs. Pet Behaviour Science 5: 1-12. [CrossRef]

Spruin, Elizabeth, Nicole Holt, Ana Ferdandez, and Anke Franz. 2016. The use of dogs in the courtroom. In Crime and Criminal Behaviour. Edited by Analise Klein. New York: Nova Science Publishers, pp. 1-10.

Spruin, Elizabeth, Katarina Mozova, Tammy Dempster, and Susanna Mitchell. 2019a. Exploring the impact of specially trained dogs on the court experiences of survivors of sexual offending in England and Wales: An exploratory case study. European Journal on Criminal Policy and Research. [CrossRef]

Spruin, Elizabeth, Katarina Mozova, Anke Franz, Susanna Mitchell, Ana Fernandez, Tammy Dempster, and Nicole Holt. 2019b. The use of therapy dogs to support court users in the waiting room. International Criminal Justice Review 29: 284-30. [CrossRef]

Stake, Robert E. 1978. The case study method in social inquiry. Educational Researcher 7: 5-8. [CrossRef]

Stake, Robert E. 1995. The Art of Case Study Research: Perspective in Practice. London: Sage.

Stapleton, Mary. 2016. Effectiveness of animal assisted therapy after brain injury: A bridge to improved outcomes in CRT. NeuroRehabilitation 39: 135-40. [CrossRef] [PubMed] 
Svedin, Carl G., and Kristina Back. 2003. Why Don't They Tell? About Being Exploited in Child Pornography. Stockholm: Rädda Barnen.

Tashakkori, Abbas M., and Charles B. Teddlie. 2003. Handbook of Mixed Methods in Social and Behavioral Research. Thousand Oaks: Sage.

Tellis, Winston M. 1997. Introduction to case study. The Qualitative Report 3: 1-14.

Victims' Commissioner. 2016. What Works in Supporting Victims of Crime. London: Office of the Victims Commissioner.

Walsh, Paul G., Peter G. Mertin, Don F. Verlander, and Cris F. Pollard. 1995. The effects of a "pets as therapy" dog on persons with dementia in a psychiatric ward. Australian Occupational Therapy Journal 42: 161-66. [CrossRef]

Weems, Noreal. 2013. Real or fake: Animals can make a difference in child abuse proceedings. Mid-Atlantic Journal on Law and Public Policy 117: 117-31.

Wells, Deborah L. 2009. The effects of animals on human health and well-being. Journal of Social Issues 65: 523-43. [CrossRef]

Wemmers, Jo-Anne, Rien Van der Leeden, and Herman Steensma. 1995. What is procedural justice: Criteria used by Dutch victims to assess the fairness of criminal justice procedures. Social Justice Research 8: 329-50. [CrossRef]

Westmarland, Nicole, and Geetanjali Ganjoli. 2012. International Approaches to Rape. Bristol: Policy Press.

Wheatcroft, Jacqueline M., Graham F. Wagstaff, and Annmarie Moran. 2009. Revictimizing the victim? How rape victims experience the UK legal system. Victims and Offenders 4: 265-84. [CrossRef]

Wright, Richard. 1984. A note on attrition of rape cases. British Journal of Criminology 25: 399-400. [CrossRef]

Yang, Hai-Peng, Liwei Wang, Liqun Han, and Stephani C. Wang. 2013. Nonsocial functions of hypothalamic oxytocin. ISRN Neuroscience 2013: 179272. [CrossRef]

Yin, Robert K. 1984. Case Study Research: Design and Methods, 1st ed. Beverly Hills: Sage Publishing.

Yin, Robert K. 1994. Case Study Research: Design and Methods, 2nd ed. Beverly Hills: Sage Publishing.

Yin, Robert K. 2003. Case Study Research: Design and Methods, 3rd ed. Thousand Oaks: Sage Publishing.

Youth Justice and Criminal Evidence Act. 1999. Available online: http://www.legislation.gov.uk/ukpga/1999/23/ contents (accessed on 20 May 2020).

Zimmer, Randi M. 2014. Partnering Shelter Dogs with Prison Inmates: An Alternative Strategy to Reduce Recidivism and Teach Social Therapy. Master's thesis, American Public University, Charles Town, WV, USA. 